\title{
Urban Mining: A Process Designed to Recover Au from E-waste
}

\author{
Fernanda Nicolle Pinheiro Nicolai ${ }^{1, ~}$, Sebastiana Luiza de Bragança Lana ${ }^{1,2}$ \\ ${ }^{1}$ Thematic Network in Materials Engineering (REDEMAT), Ouro Preto State University, Ouro Preto City, Brazil \\ ${ }^{2}$ Department of Post-Graduation in Design/School of Design of Minas Gerais State, Minas Gerais State University (UEMG), Belo Horizonte \\ City, Brazil
}

Email address:

nicollenicolai $a$ gmail.com (F. N. P. Nicolai), sebastiana.lana $a$ gmail.com (S. L. de B. Lana)

*Corresponding author

\section{To cite this article:}

Fernanda Nicolle Pinheiro Nicolai, Sebastiana Luiza de Bragança Lana. Urban Mining: A Process Designed to Recover Au from E-waste. International Journal of Sustainable Development Research. Vol. 5, No. 2, 2019, pp. 30-40. doi: 10.11648/j.ijsdr.20190502.11

Received: January 16, 2019; Accepted: February 26, 2019; Published: July 1, 2019

\begin{abstract}
Electronic waste (e-waste) is today the fastest growing solid waste in the world, due to its unique characteristics like planned obsolescence, high technology and a fast growing consumer market. It can contain over 100 highly toxic and potentially hazardous substances to human health and to the environment. However, e-waste is a valuable secondary source of high quality finite raw minerals suitable for "urban mining" in which the materials contained should not be lost. The recovery materials from e-waste, also called Reverse Logistics (RL), which includes the insertion and application of sustainable Design, is an environmental and commercial measure of great importance that can only bring benefits to all involved. Unconventional pre-treatments techniques to separate gold-rich components and other parts of e-waste from motherboards, Printed Circuit Boards (PCBs) and cell phone plates has not been extensively explored in literature. The aim of this paper is to describe a set of thermo-mechanical and manual techniques in pilot scale to separate gold-rich parts from the others of the e-waste mentioned above. Another goal of this research is to obtain the total mass of gold deposited on the three samples of selected connector tabs from PCBs. Scanning Electron Microscopy (SEM) technique was performed and the results were analyzed. With this procedure, the total gold mass could be evaluated.
\end{abstract}

Keywords: E-waste, Urban Mining, Recycling Designing Process, Separation Techniques, Gold (Au) Recovery, SEM

\section{Introduction}

Almost all the electronic waste (e-waste) that is gold-rich and also presents other metals with high economic values such as tin, iron, basic metals and rare metals contained in motherboards, Printed Circuit Boards (PCBs) and cell phone plates (Figure 1) are currently been exported from Brazil.

According to relevant literature, there is an apparent geographic and socio-economic division for e-waste handling patterns across the globe [1]. It is often mentioned that e-waste is exported from developed countries such as Canada, European countries, among others to developing countries like India, African countries, etc. [1-4]. Brazil as a developing country is an exception regarding e-waste containing gold-rich exportation. On the other hand, some developed countries such as The USA has forbidden e-waste exportation in some states [5]. However, it should be noted that any figures concerning the exportation statistics is only a rough estimation and cannot be authenticated, due to the clandestine nature of this operation [4]. The introduction of innovative technologies and development of e-waste treatment systems should be combined systematically with the socio-economic local context [1], to take into account this clandestine procedure.

University groups in Brazil have been researching the optimization of e-waste recycling processes. However, there is still much to be done to enable a more efficient recovery of the materials, which could be considered as an economic factor especially for developing countries [6]. By avoiding e-waste exportation, the valuable materials stay in the country, improving the local economy.

Brazil generates the second greatest quantity of e-waste among developing countries, as it is the fifth largest producer of computers in the world. Moreover, electrical and electronic 
equipment is one of the most dynamic sectors of the economy, comprising $4.1 \%$ of Brazilian gross domestic product [2].

Motherboards present complex materials composition that can have a significant impact on recycling requirements and adequate processes, including emission control $[3,7,8]$.

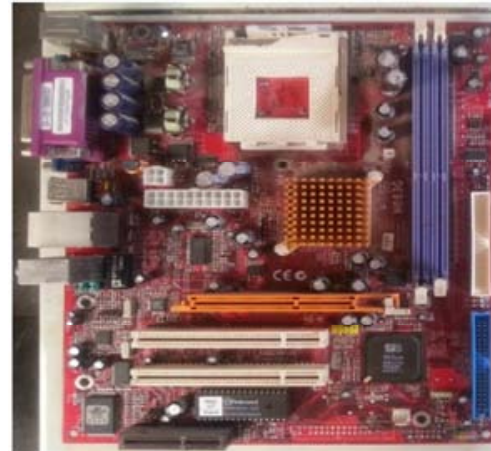

(a)

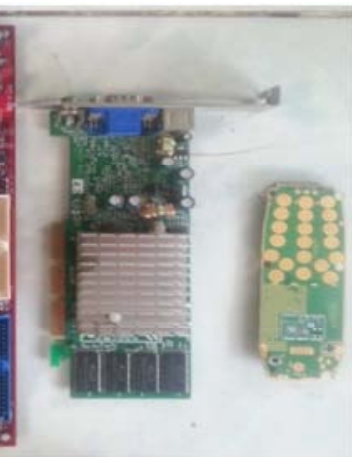

(b) (c)
Figure 1. Motherboard (a), Printed Circuit Board - PCB (b) and cell phone plate (c) ready to be submitted to thermo-mechanical and manual separation of the parts containing gold-rich. Source: the authors.

PCBs is described in literature as the heart of virtually all electronic wastes, constituting 3\% the total weight of the whole electronic waste [4]. Since PCBs waste are considered as the "rich mines of wealth", less energy would be required to extract and refine the precious metals compared to the unsustainable mining of virgin ores [4]. Various treatment scenarios to recycle PCBs can be configured by interlinking different pre-processing options, which will produce different results $[1,4]$.

Thousands of cell phones are consumed all over the world annually [2, 3]. In $2015,96.9 \%$ of the population in the world is using mobile phones [9]. Brazil is in the fifth position in the world ranking of mobile access, behind China, India, USA and Russia [2]. A large variety of materials is applied in these kinds of devices and this is where the complexity to fully recycle them reside. A printed circuit board of a mobile phone weighs $15-43 \%$ of the device's total weight. It contains about $30 \%$ of metals and $70 \%$ of non-metals [9]. In one ton of mobile phones' waste, $340.0 \mathrm{~g}$ of gold $(\mathrm{Au}), 3.5 \mathrm{Kg}$ of silver $(\mathrm{Ag}), 140.0 \mathrm{~g}$ of palladium $(\mathrm{Pd})$, and $130.0 \mathrm{Kg}$ of copper $(\mathrm{Cu})$ were found [9].

Any sustainable recycling solution must be environmentally correct, transferable and applicable in practice and must be payable, specially the e-waste considering its high recyclable potential $[3,10,11]$ It is interesting to notice that the best routes to follow will depend on the type of e-waste and its hazard/risk potential, regional aspects, and professionals involved $[2,11]$.

E-waste incineration is dangerous [8] and carcinogen due to the presence of bisphenol contained in the chemical composition of its polymeric encapsulations [1, 3, 4, 11]. Polymeric encapsulations are present in motherboards connectors and slot connectors, cell phone plate's components, and PCBs' slot connectors as it can be seen in Figure 2. It should be separated before incineration due to its toxicity when incinerated $[3,6,11]$.

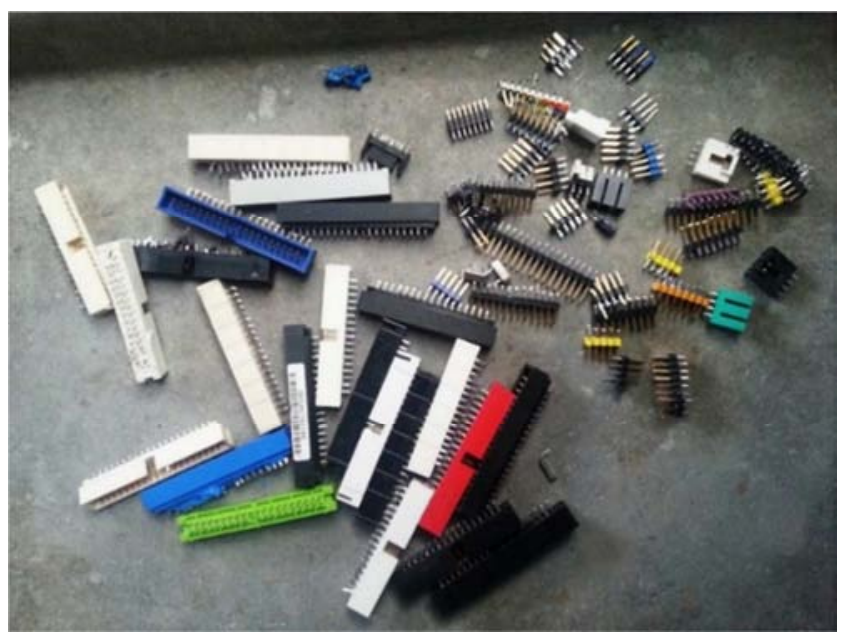

Figure 2. Polymeric encapsulations of motherboards' connectors, slot connectors, and PCBs' connectors along with its gold-rich pins. Source: the authors.

Polymeric parts constitute $21 \%$ of the e-waste [11] which contains brominated flame retardants (BFRs) that may rise to dioxins and furans during incineration. Other substances and metals that can be present are gold, tin, silver, nickel and cooper amongst others, which may act as catalysts to increase the dioxins formation during incineration [4]. The disadvantage of e-waste incineration is the large amount of these residues, including the generation of inefficient secondary raw material and the air pollution [11]. Moreover, it is a fact that pollution rates are increasing on the planet $[7,12]$. It is possible to collect the gases generated during e-waste's incineration under high cost $[8,11]$, and on top of it, incineration causes the loss of at least $20 \%$ of gold, which makes this process impracticable [1].

Environmentally correct e-waste treatment technology was identified with the first level including decontamination, dismantling and segregation. Mechanical and manual processes should be seen as an initial phase, since both are important steps in the e-waste recycling context. Mechanical separation and selective dismantling can be optimally combined to have the most cost-effective liberation result, without breaking its original form and materials and these processes have the advantage of being relatively cheaper than incineration. The optimization of these chain processes and its interface is the challenge to overcome. A proper segregation of the gold-rich parts is required to avoid loss of gold, contaminations from others metals, toxic burning preventing environment pollution and human contamination $[1,3,8]$.

The aim of this paper is to describe a set of thermo-mechanical and manual techniques in pilot scale to separate gold-rich parts from the other parts of specific types of e-waste mentioned above. Another goal of this research is to obtain the total mass of gold deposited on the three samples of selected connector tabs from PCBs. Initially, Scanning Electron Microscopy (SEM) technique was used to confirm the presence of $\mathrm{Au}$ on the samples and then after to access the thickness of Au deposition on 1 tab of each sample. In this way, 
the total mass of Au on each sample was calculated and the results were analyzed.

\section{Materials and Methods}

\subsection{Selected Types of e-waste}

The materials to be contemplated in this work are motherboards, PCBs and cell phone plates, commonly found in large quantities in both informal and formal markets of Belo Horizonte City, Minas Gerais State, Brazil (Figure 1).

\subsection{Methods}

Despite of the large materials variety present in the chosen e-waste, the methodology applied can be seen in Figure 3.

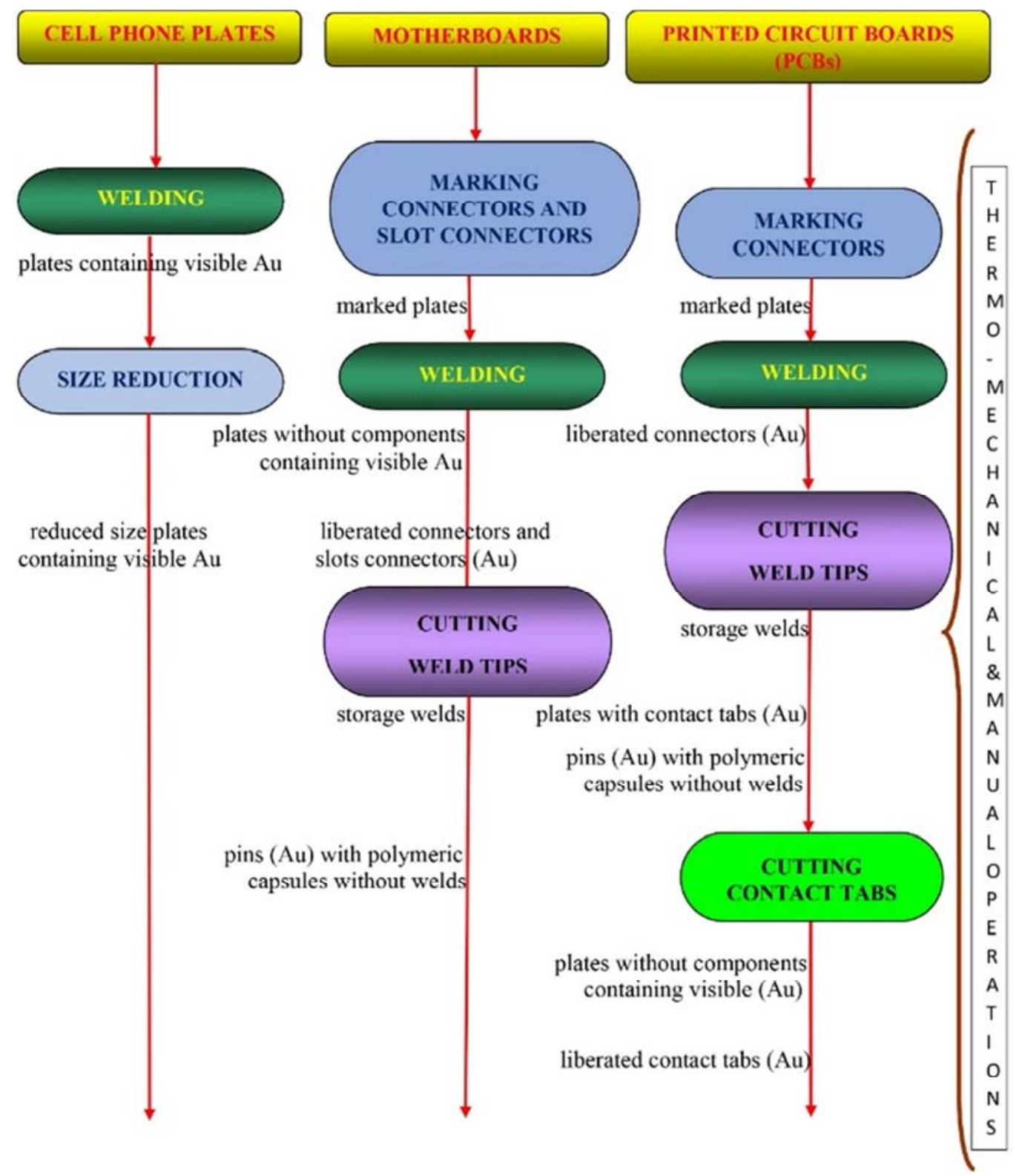

Figure 3. Flowchart of the methodology steps applied to the e-waste contemplated in this research. Source: the authors.

A relevant observation is that most studies do not directly provide the systematic solutions for treating these materials. Generally, the aim is the environmental, social and economic performances balance. Moreover, it is not fully explained in details the separation techniques of parts containing gold present in the e-waste before being submitted to the next treatment processes as can be noticed in the patent US4426225 A, for example [13]. The general common technique will be explained and some specific details at each material will be highlighted.

\subsubsection{Thermo-mechanical and Manual Technique}

A) Applied to motherboards and PCBs

One good reason to apply thermo-mechanical and manual technique to separate e-waste parts is due to a possible complete recycling of each component. In this way, each kind 
of material present such as polymers, others metals, among others will be more easily recovered and/or reused.

Each motherboard plate (Figure 4a) and PCB (Figure 4b) were marked on the back of its visible gold-rich components. The marked parts were desoldered on a metallic surface with a fixed semi-industrial air blowing directly at the welding points (Figure 4c) until the total liberation of the connectors and slot connectors are concluded. This process was facilitated by using a metal spatula.

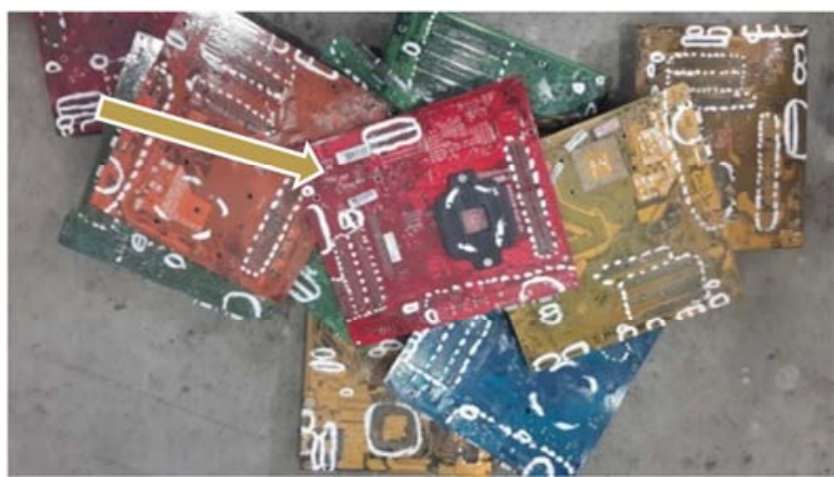

(a)

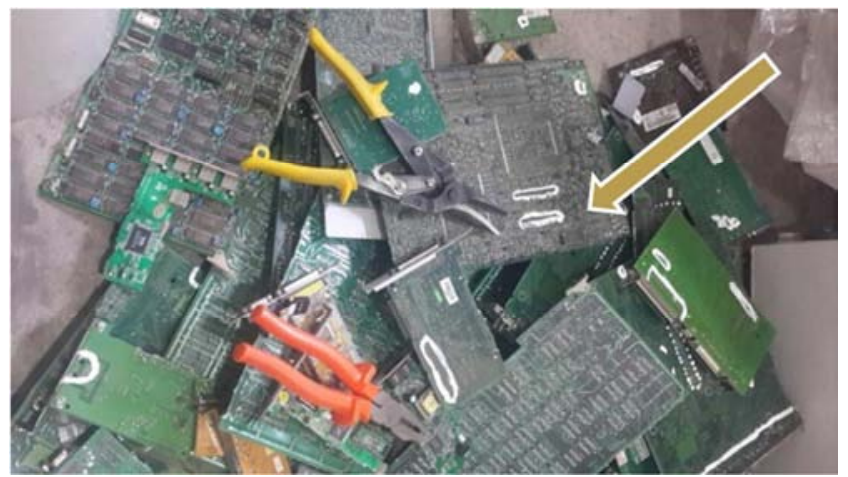

(b)

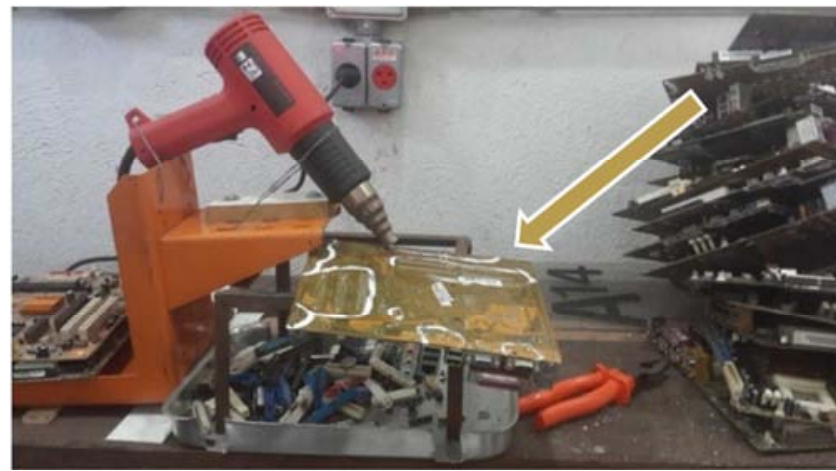

(c)

Figure 4. Motherboards (a) and PCBs (b) marked on the back, then thermo-mechanically and manually desoldering the gold-rich components (c). Source: the authors.

The connectors and slot connectors (Figure 5) were then treated with a fine cutting saw machine (Figure 6), which was used upside down to hold the connectors and slot connectors.

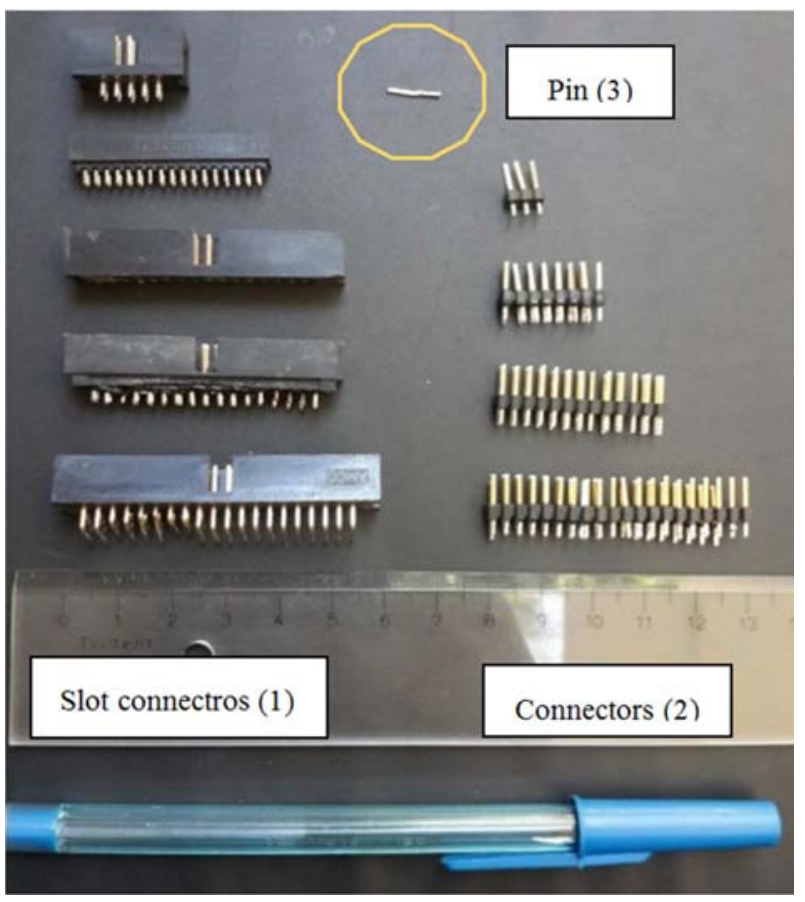

Figure 5. Different sizes of slot connectors (1) and connectors (2) desoldered and totally liberated. Detail of a pin (3) still with weld of $\mathrm{Pb} / \mathrm{Sn}$ and/or $\mathrm{Sn} / \mathrm{Ag} / \mathrm{Cu}$. Source: the authors.

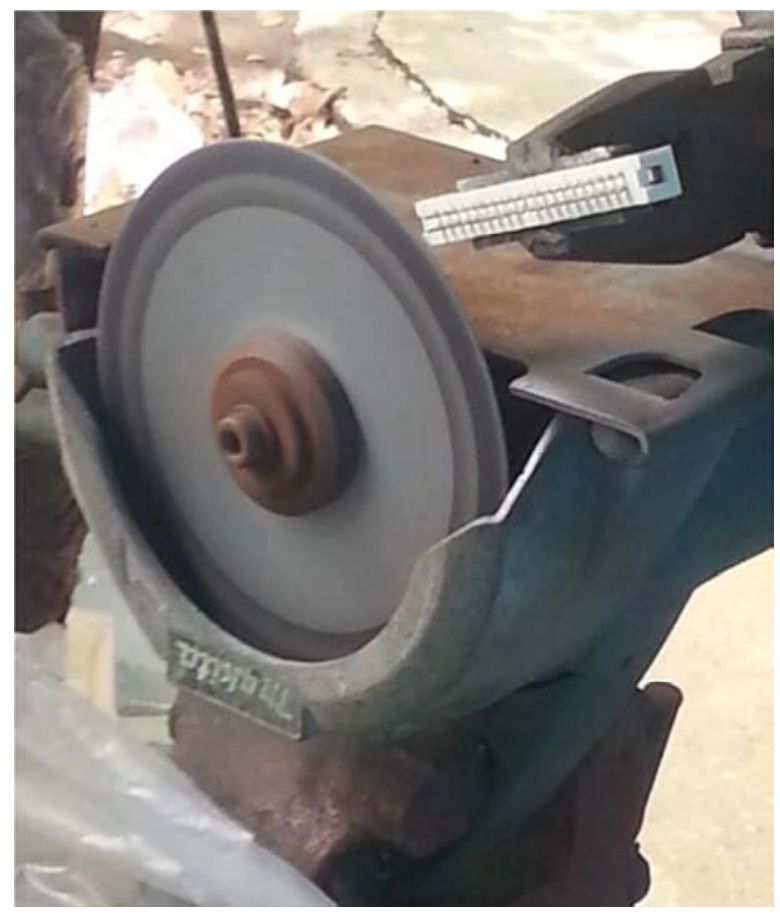

Figure 6. Saw machine used upside down along with an especial adapted tool (indicated with arrow) to hold the slot connector aiming at taking out the weldings of $\mathrm{Pb} / \mathrm{Sn}$ and/or $\mathrm{Sn} / \mathrm{Ag} / \mathrm{Cu}$. Source: the authors.

The saw machine was used not only to liberate the gold contaminants, such as $\mathrm{Pb} / \mathrm{Sn}$ and/or $\mathrm{Sn} / \mathrm{Ag} / \mathrm{C}$, but also to recycle them (Figure 7). Tin (Sn) is the second metal of highest value found in motherboard plates after gold [8]. The typical $\mathrm{Pb} / \mathrm{Sn}$ 's weld present in scrap originated from printed circuit boards ranges between $4-6 \%$, and so lead $(\mathrm{Pb})$ represents $2-3 \%$ of the weight of the original board [11]. 


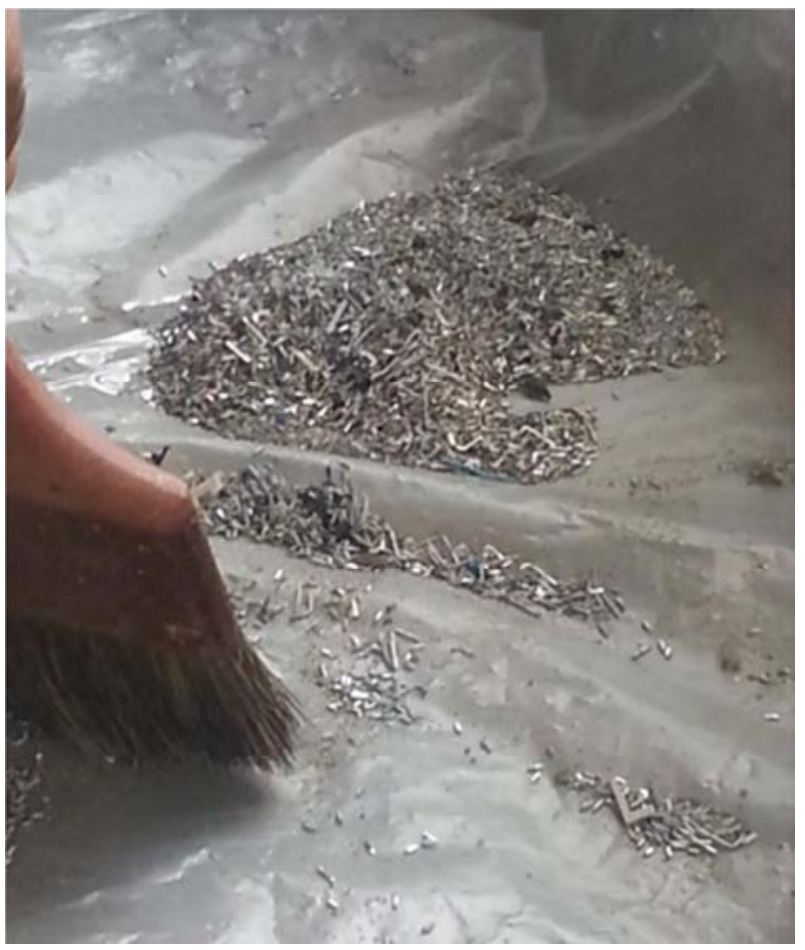

Figure 7. Connectors and slot connectors' weldings separated from their polymeric capsules and pins. Source: the authors.

After these processes, liberated pins with a thin gold coat were gotten (Figure 8).

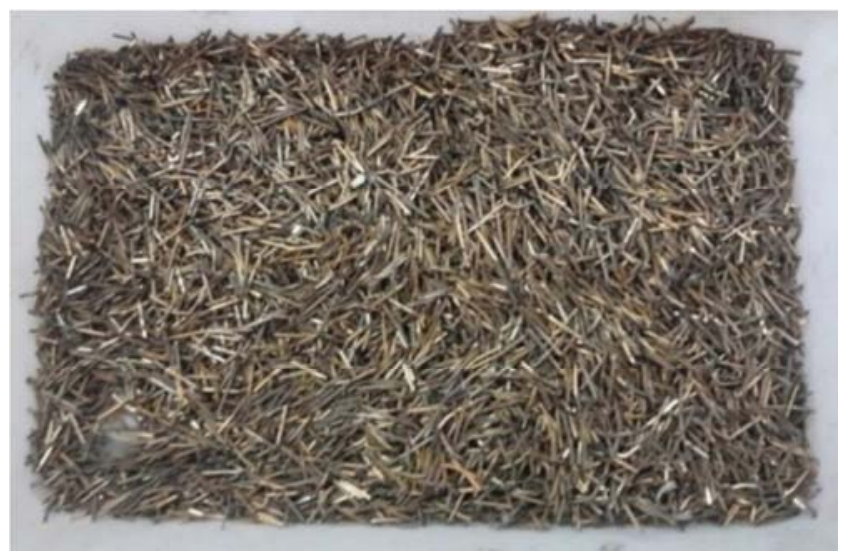

Figure 8. Liberated pins without welding tips of $\mathrm{Pb} / \mathrm{Sn}$ and/or $\mathrm{Sn} / \mathrm{Ag} / \mathrm{Cu}$. Source: the authors.

The polymeric capsules (Figure 5) as well the welding tips of $\mathrm{Pb} / \mathrm{Sn}$ and/or $\mathrm{Sn} / \mathrm{Ag} / \mathrm{Cu}$ were stored and then addressed to the Association of Collectors of Papers, Cardboards and Recyclable Materials (ASMARE) at Belo Horizonte City to be reused and/or recycled [14].

B) Applied to cell phone plates

The same thermo- mechanical and manual process performed to motherboards and PCBs was applied to the cell phone plates (Figure 9a). Each component was segregated and then taken to be either recovered or reused due to its wide range of high-value materials. After desoldering, the cell phone plates (Figure 9b) were cut into small pieces with specific scissors (Figure 9c).

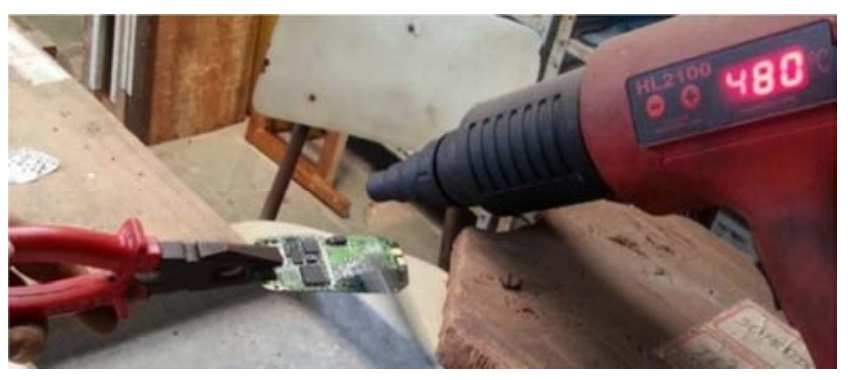

(a)

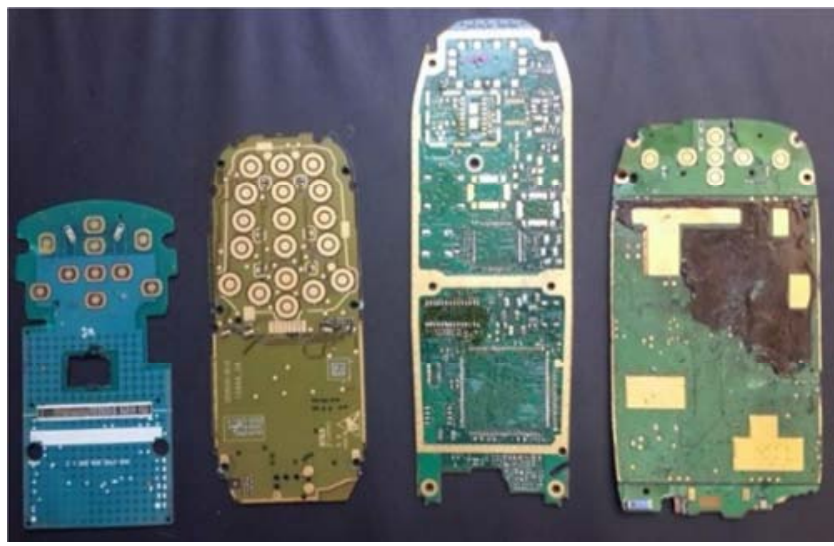

(b)

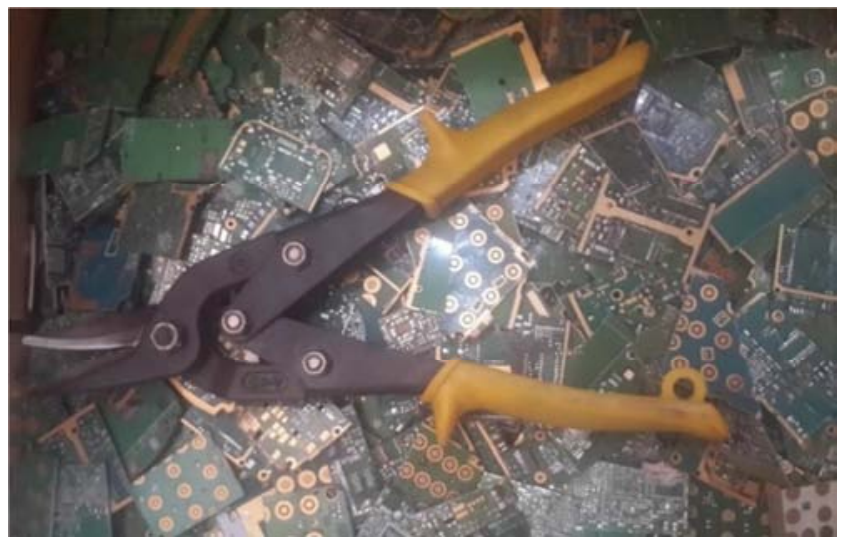

(c)

Figure 9. Cell phone plate being desoldered with a semi-industrial air blowing (a) with the components already desoldered (b) and cut into small pieces (c). Source: the authors.

\subsubsection{Segregation of PCBs' Connector Tabs}

The characteristic of the PCBs plates is that it has connector tabs (Figure 10) containing gold-rich deposited layers along with other metals on a fiber glass reinforced matrix composite $[4,15]$. These contact tabs were manually removed with a suitable metal cutting scissors, along with a regular plier.

The saw machine was not used to take the contact tabs out to avoid the large amount of toxic dust generated in this kind of process. The contact tabs contain flame retardants at a level of $15 \%$ [4]. The main flame retardant material used in circuit boards is tetrabromobhisphenol-A (TBBPA) [11]. 


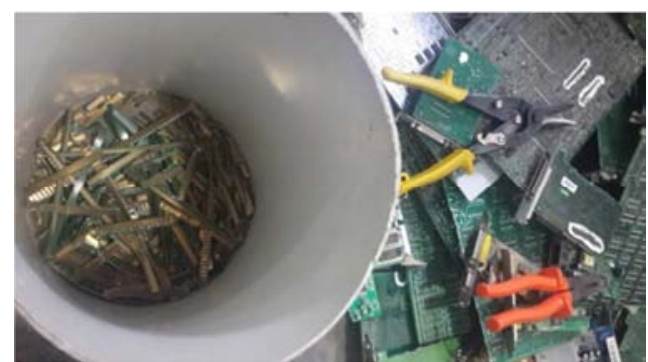

Figure 10. $P C B$ s and its contact tabs containing gold rich already liberated. Source: the authors.

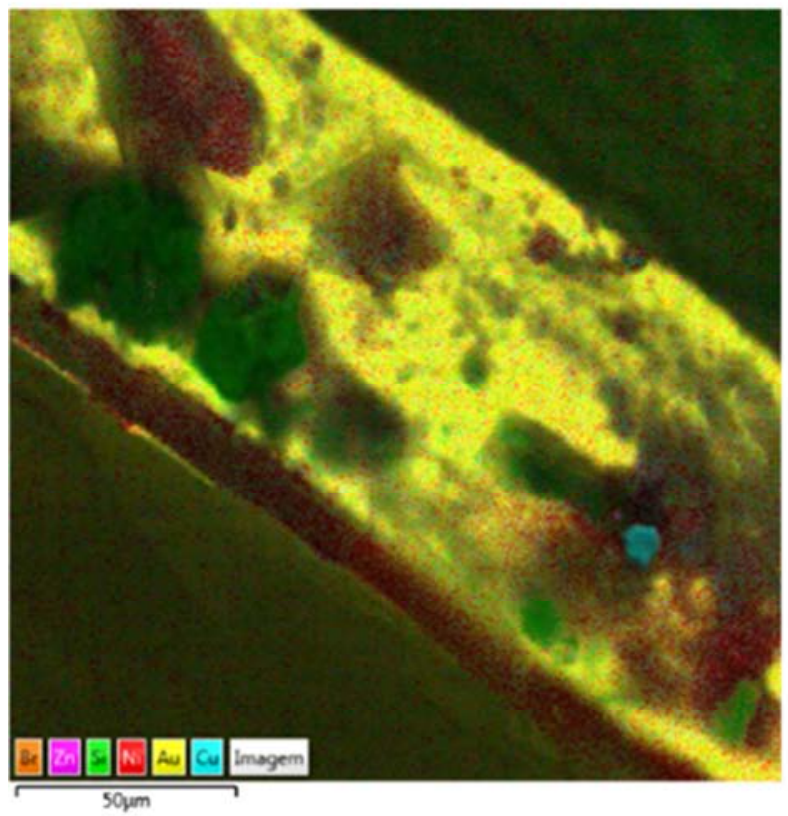

\subsubsection{Determination of the Mass of Gold Deposition in Contact Tabs of PCBs Through Scanning Electron Microscope (SEM)}

Three groups of samples of contact tabs were visually separated, each one with approximately the same color and the same geometry of the gold deposition. One sample of each group was taken to be analyzed by a Scanning Electron Microscopy (SEM) in an attempt to search the presence of gold deposited (Figures 11, 12 and 13).

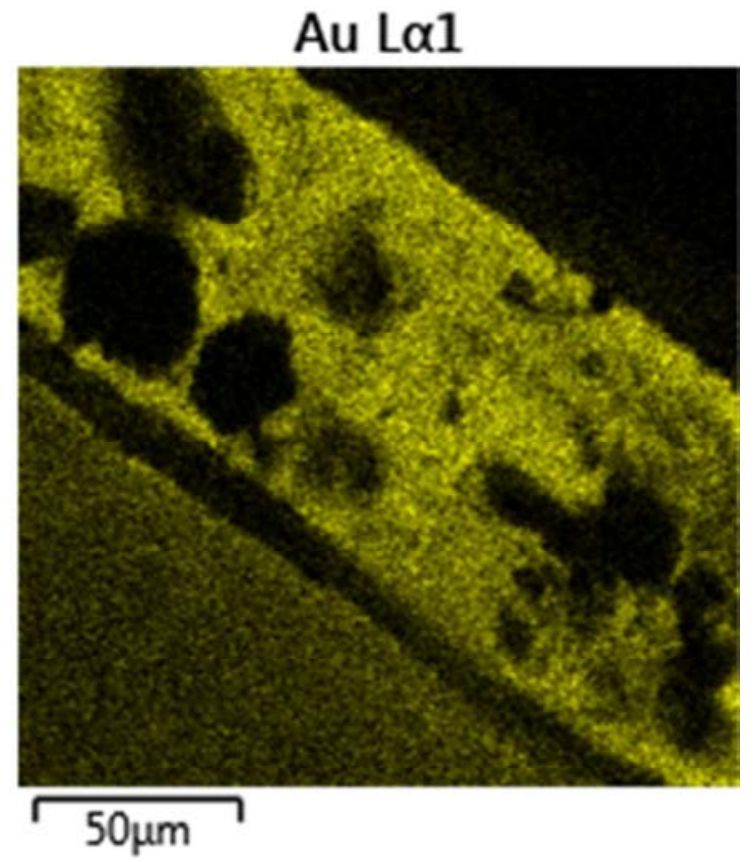

Figure 11. Top view scanning showing gold deposition on sample 1. Source: the authors, REDEMAT. 


\section{Au $M \alpha 1$}
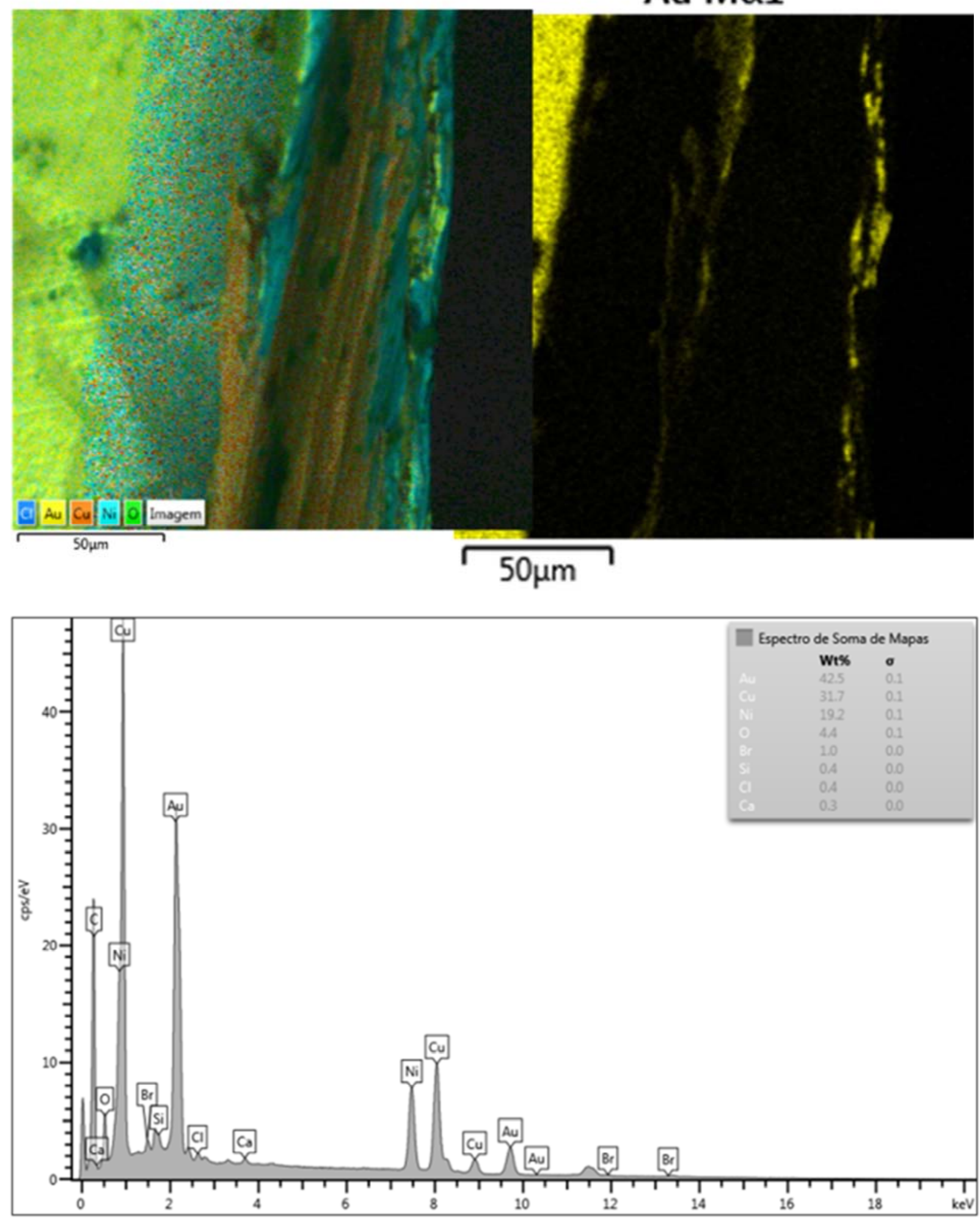

Figure 12. Top view scanning showing gold deposition on sample 2. Source: the authors, REDEMAT. 


\section{$\mathrm{Au} M \alpha 1$}
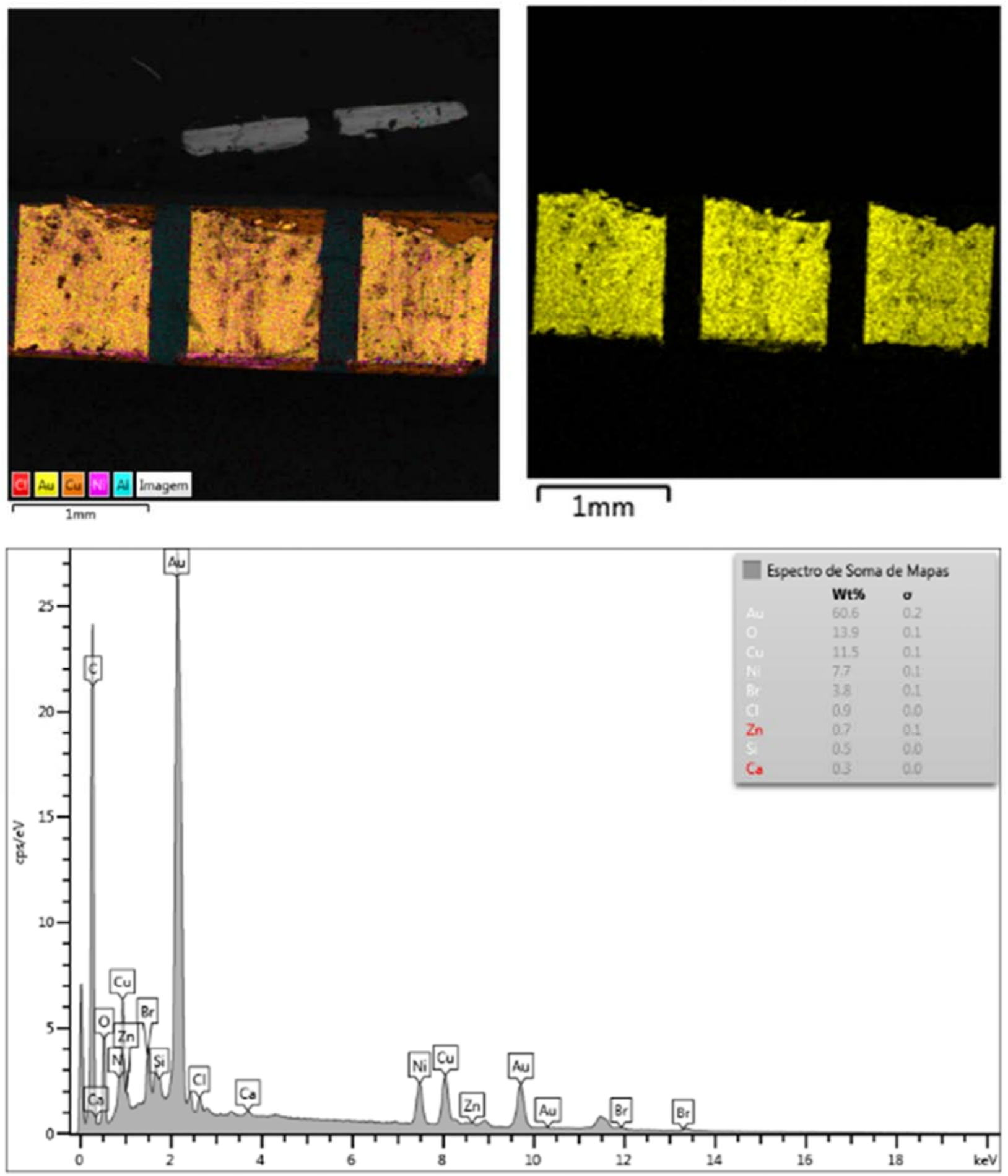

Figure 13. Top view scanning showing gold deposition on sample 2. Source: the authors, REDEMAT.

It was possible to certify through the SEM analysis the presence of gold on the three samples' top view. However, it is well known that SEM's top view scanning refers only to the measurement of the surface of the gold deposited and not the real thickness of its deposition. In this way, an attempt to measure the thickness of the gold deposition layers on the specimen through SEM microscope, it was required new measurements of these layers using a magnifying glass to enable the subsequent calculations based on its width and length, as it can be seen in Figures 14, 15 and 16. 


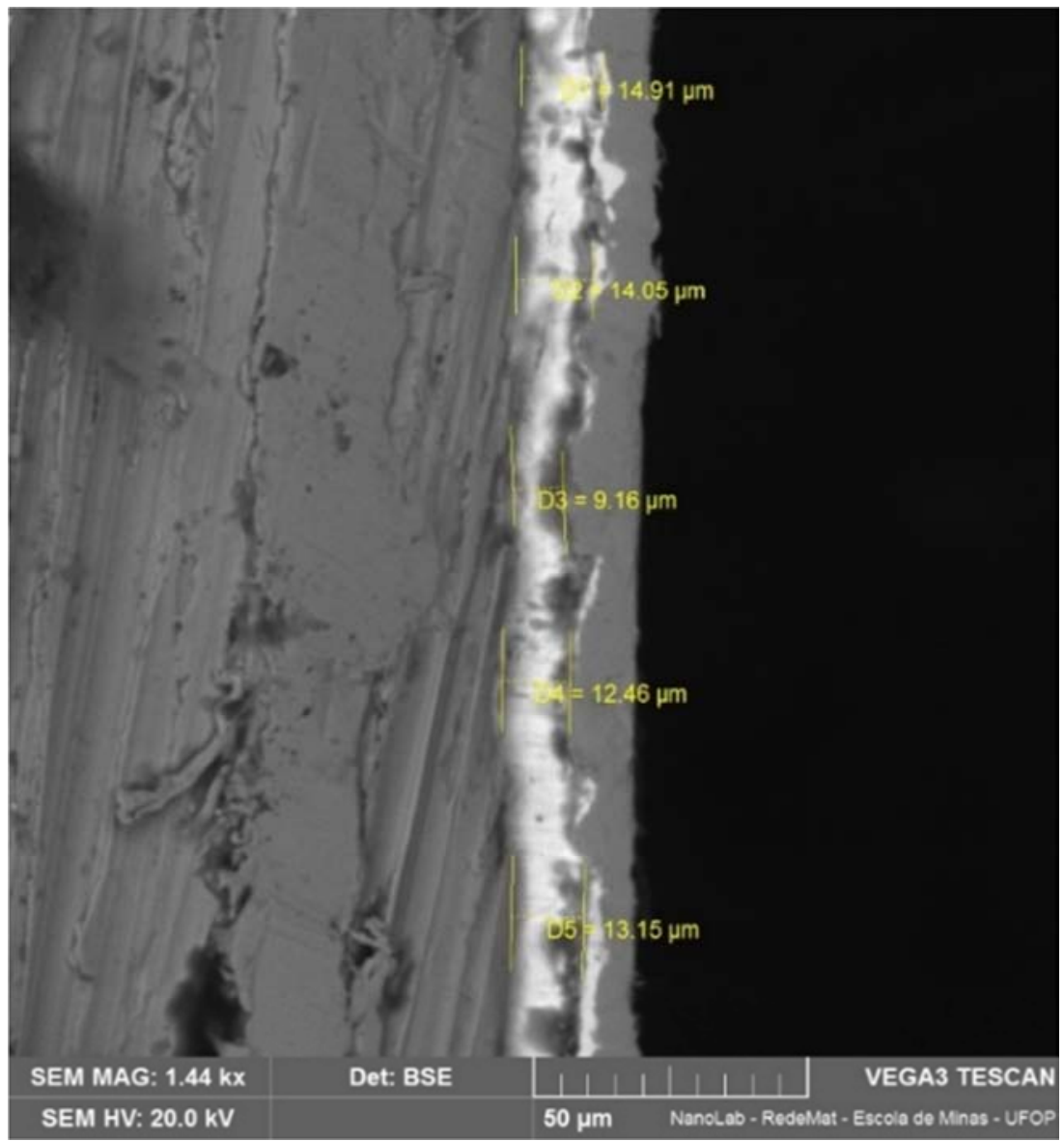

Figure 14. Thickness of gold deposition layer on sample 1: 1,44x magnification (SEM). Source: the authors, REDEMAT.

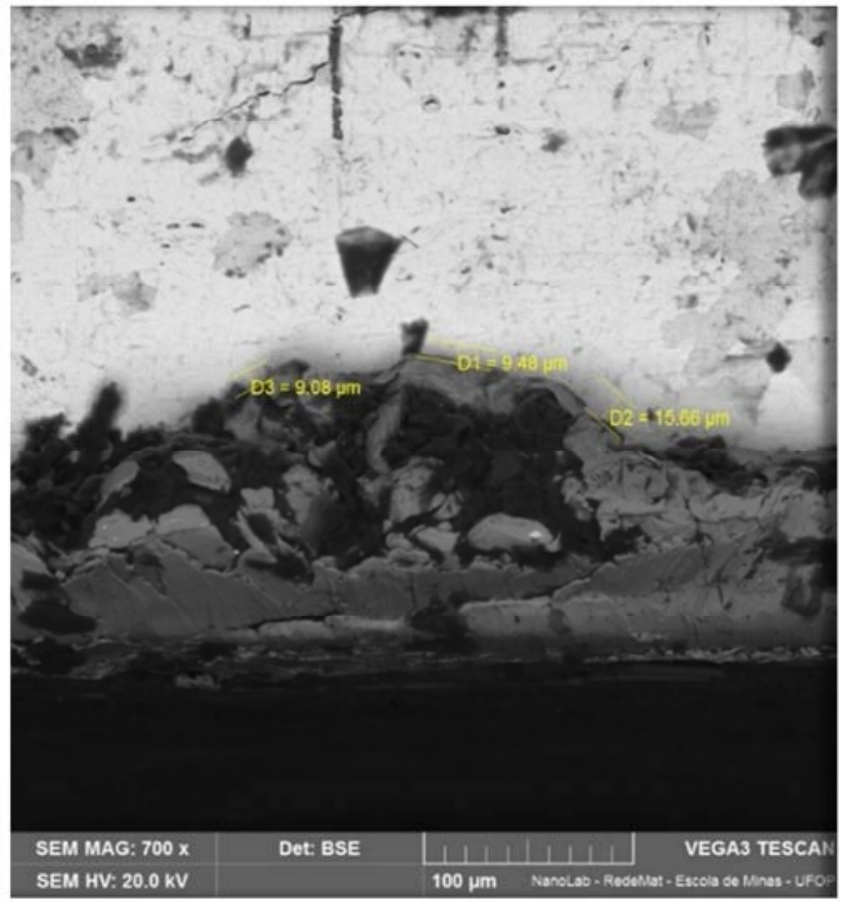

Figure 15. Thickness of gold deposition layer on sample 2: 700x magnification (SEM). Source: the authors, REDEMAT.

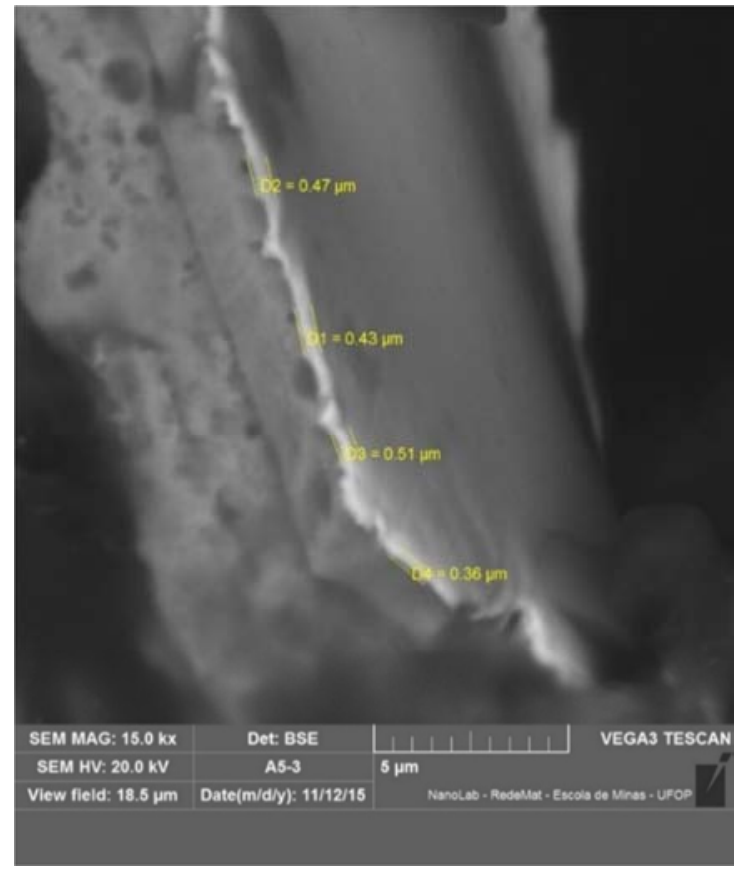

Figure 16. Thickness of gold deposition layer on sample 3: 15x magnification (SEM). Source: the authors, REDEMAT.

From the average results of these measurements the volumes were calculated (Table 1) using the gold's full density $(\rho)$. 
Table 1. SEM results with optical measurements and total mass of gold deposition on each tab of the three contact tab samples.

\begin{tabular}{|c|c|c|c|c|c|}
\hline $\begin{array}{l}\text { Contact tabs' } \\
\text { samples }\end{array}$ & $\begin{array}{l}\text { Thickness of gold } \\
\text { deposition of } 1 \mathrm{tab} \\
\text { SEM }\left(\mu \mathrm{m} \text { or } \mathrm{cm}^{2} 10^{-4}\right)\end{array}$ & Width of 1 tab (cm) & Length of $1 \mathrm{tab}(\mathrm{cm})$ & $\begin{array}{l}\text { Volume of gold } \\
\text { deposition on } 1 \text { tab } \\
\text { SEM }\left(\mathrm{cm}^{3} \times 10^{-4}\right)\end{array}$ & $\begin{array}{l}\text { Total mass of gold } \\
\text { deposition on } 1 \text { tab } \\
\text { SEM }\left(g_{10} 10^{-4}\right)\end{array}$ \\
\hline Sample 1 & 12.756 & 0.15 & 0.35 & 0.670 & 12.73 \\
\hline Sample 2 & 11.407 & 0.10 & 0.50 & 0.570 & 10.83 \\
\hline Sample 3 & 0.442 & 0.10 & 0.50 & 0.022 & 0.42 \\
\hline
\end{tabular}

A contact tab is composed of variable number of tabs. As three samples were measured, the total mass of gold deposition of each contact tab is shown in Table 2 .

Table 2. Total mass of gold deposition contained in three different contact tab samples through SEM..

\begin{tabular}{llll}
\hline $\begin{array}{l}\text { Contact tabs' } \\
\text { samples }\end{array}$ & $\begin{array}{l}\text { Total number of tabs in 1 contact tab } \\
\text { (front and back) }\end{array}$ & $\begin{array}{l}\text { Mass of gold deposition on 1 tab } \\
\text { SEM (gx10-4) }\end{array}$ & $\begin{array}{l}\text { Total mass of gold deposition on 1 contact tab } \\
\text { SEM (gx10-4) }\end{array}$ \\
\hline Sample 1 & 120 & 12.73 & 1527.6 \\
Sample 2 & 150 & 10.83 & 1624.5 \\
Sample 3 & 92 & 0.42 & 38.64 \\
\hline
\end{tabular}

A source of errors that will influence the results can be related to the gold deposition deformation (porosities, discontinuities/defects and deformities) as it can be easily seen in Figures 12, 13 and 14. This will lead to an error of using the gold density to calculate the total mass as in Tables 1 and 2 .

Table 2 shows quite different amounts of the total mass of gold deposited on the samples 1 and 2 from the sample 3 . This could be due to the various methods of gold deposition applied to connector tabs over the years. Additionally, non-ferrous metals as precious metals contents have gradually decreased in concentration in scrap [16].

Hemsley (1988) observed that during the production experience of the first generation of automated tab plating units, it was found that the distribution of plated nickel and gold on the board tabs were uneven and this were seen in these samples. Such uneven distribution in production operations resulted in up to 40 per cent excess metal being plated in order to achieve the specified thickness.

The choice of a suitable gold coating thickness depends on the durability degree and environmental protection required by the application. Due to the high cost of gold, it is prudent to keep the gold coating thickness as low as is appropriate for the application requirements. Increasing the thickness of a hard gold coating increases durability and tends to decrease the porosity that reduces the contacts' vulnerability to pore corrosion [16].

In addition, contacts with gold coating thickness between 0.03 microns and 2.5 microns exhibit stable low contact resistance at normal forces measured down to 10 grams. Thinner gold coatings have lower durability which means that the contact can withstand less insertion cycling, fretting, mechanical vibration, etc. before wear-through to the base metal occurs. Once the contact interface motion has resulted in wear-through of the gold coating, fretting degradation of the base material takes place. Nowadays, 3/4 micrometer of gold with nickel under plate is recommended. However, there is no average scrap composition, even when the values given as typical averages actually only represent scrap of a certain age and manufacturer $[3,16,17]$.

\section{Conclusions}

Three types of e-waste motherboards, Printed Circuit Boards (PCBs) and cell phone plates were chosen as an attempt to segregate their gold-rich parts. They presented different assembly characteristics originating from factory where they were produced. For the purpose to obtain the highest recycling rate of gold, the best scenario is to combine full manual dismantling with thermo-mechanical techniques for gold-rich disassembly fractions.

Thermo-mechanical and manual techniques applied to motherboards and PCBs showed to be very useful due to the necessity to separate gold-rich connectors and slot connectors from the boards since the pins should be totally liberated before the subsequent hydrometallurgical processes. It avoids toxic incineration of e-waste polymeric parts and loss of gold content. These processes found to be quiet safe to work with no danger for human health if safety equipment is properly utilized.

The use of a saw machine to cut the welding points containing $\mathrm{Pb} / \mathrm{Sn}$ and/or $\mathrm{Sn} / \mathrm{Ag} / \mathrm{Cu}$ out of the connectors, slot connectors and pins was extremely important. It was necessary not only due to the segregation of hazardous gold contaminant metals such as lead $(\mathrm{Pb})$, but also due to the separation of high economic value metals such as tin ( $\mathrm{Sn})$ and silver (Ag).

The thermo-mechanical and manual processes performed on cell phone plates are useful to remove almost all components, leaving the plates nearly free.

An advantage of the thermo-mechanical and manual processes applied to countries in development is that labor under environment health and safety standards will preserve abundant jobs for the informal sectors, increasing local subsistence. In this connection, e-waste should be treated as raw material and locally recycled. Knowing that all of these precious metals should be used in a high purity degree, the use of the term urban mining can be considered suitable to call these e-waste recovering processes as opposed to mining and subsequent treating of raw ores. The average of gold deposited 
in contact tabs of PCBs through SEM was $0,106358 \mathrm{~g}$. Considering the gold price in June 24 of 2016 was 42.38USD\$ per gram. In this way, contact tabs of PCBs has around 5,0USD\$ in gold. Literature shows that the same amount of gold that can be found in 5 ton of e-waste can also be found in 60ton of auriferous ore $[8,18]$.

SEM technique to determine the amount of gold deposited on e-waste connector tabs was not very precise due to the presence of porosities, discontinuities/defects and deformities. This technique might be relevant for quality control of new connector tabs that might not present such defects after the piece production. The variations of the $\mathrm{Au}$ depositions geometry lead to a not accurate determination of the total mass of gold in connector tabs of PCBs. It is a known fact that the thickness of the gold depositions in electronics is decreasing every year, ever since deposition technologies advance. New ways to evaluate the amount of gold rich layers should be researched.

\section{Acknowledgements}

A very special thanks to Mr. Luiz Fernando Medeiros (in memorian) for contributing in this paper with unquestioned wisdom. The authors would also like to thank CAPES (Coordenação de Aperfeiçoamento Pessoal de Nível Superior) and GORCEIX Foundation for their financial support. Thanks to the Microlab of Ouro Preto Federal State University (UFOP) and to the Center of Development of Nuclear Technology (CDTN) for their support on providing analysis facilities.

\section{References}

[1] Feng Wang, Jaco Huisman, Christina E. M. Meskers, Mathias Schluep, $\mathrm{Ab}$ Stevels, Christian Hagelüken. The Best-of-2-Worlds philosophy: Developing local dismantling and global infrastructure network for sustainable e-waste treatment in emerging economies. Waste Management, v.32, p. 2134-2146,

2012 . http://www.ewasteguide.info/files/Wang_2012_Bo2W_0.pdf.

[2] Camila Reis de Oliveira, Andréa Moura Bernardes, Annelise Engel Gerbase. Collection and recycling of electronic scrap: A worldwide overview and comparison with the Brazilian situation. Waste Management, Brazil, v. 32, p. 1592-1610, 2012.

[3] Cristian Hagelüken, Umicore Metals Refining AG \& Co. Improving metal returns and eco-efficiency in electronics recycling - a holistic approach for interface optimization between pre-processing and integrated metals smelting. IEEE International Symposium on Electronics \& Environment. San Francisco, v. 8-11, p. 218-223, May of 2006. DOI: 10.1109/ISEE.2006.1650064.

[4] Pejman Hadi, Chao Ning, Weiyi Ouyang, Meng Xu, Carol S. K. Lin, Gordon McKay. Toward environmentally-benign utilization of nonmetallic fraction of waste printed circuit boards as modifier and precursor. Waste Management, Hong Kong, v. 35, p. 236-246, 2015.
[5] Map of the United States with Legislation. http://www.ecycleclearinghouse.org/content.aspx?pageid=10.

[6] Martin Goosey, Rod Kellner. A Scoping Study End-of-Life Printed Circuit Boards. Department of Trade and Industry, UK. Shipley Europe Limited. http://www.cfsd.org.uk/seeba/TD/reports/PCB_Study.pdf.

[7] Jens Brobech Legarth, Leo Alting, Gian Luca Baldo. Sustainability issues in Circuit Board Recycling. Proceedings of the Ieee International Symposium on Electronics and the Environment. Denmark, p. 126-131, 1995. DOI: 10.1109/ISEE.1995.514963.

[8] Jirang Cui, Lifeng Zhang. Metallurgical recovery of metals from electronic waste: A review. Journal of Hazardous Materials: Science Direct, Norway, v. 158, p. $228-256$ February 8 of 2008. DOI: 10.1016/j.jhazmat.2008.02.001.

[9] M. C. Vats, S. K. Singh. Assessment of gold and silver in assorted mobile phone printed circuit boards (PCBs): Original article. Waste Management, India, v. 45, p. 280-288, 2015. DOI: $\quad$ 10.1016/j.wasman.2015.06.002. http://www.ncbi.nlm.nih.gov/pubmed/26112260.

[10] Craig R. Carter, Lisa M. Ellram. Reverse Logistics: a review of the literature and framework for future investigation. International Journal of Business Logistics, Tampa, v. 19, n. 1, p. 85-103, January of 1998.

[11] Ministry of Environment \& Forests Central Pollution Control Board, Delhi. Guidelines for Environmentally Sound Management of E-Waste. As approved vide MoEF letter No. 23-23/2007-HSMD, 12 of March of 2008. http://www.moef.nic.in/divisions/hsmd/guidelines-e-waste.pdf.

[12] William D. Callister Jr, Ciência e Engenharia de Materiais. Fifth Edition, 2002. Rio de Janeiro: Editora LTC - Livros Técnicos e Científicos Editora S. A., chapter 1, p. 1-5.

[13] Patent US4426225 A: Gold recovery method - 1984, 4,426,225. http://www.google.com.br/patents/US4426225.

[14] Association of Paper Collectors, Cardboards and Recyclable Materials (ASMARE) in Belo Horizonte city, Minas Gerais State, Brazil. http://asmare.org/.

[15] Shunli Zhang, Eric Forssberg. Mechanical separation-orients characterization of electronic scrap. Resources, conservation and recycling, number.21, p. 248 - 269, 1997. DOI: http://dx.doi.org/10.1016/S0921-3449 (97)00039-6.

[16] Tyco Electronics Corporation. AMP Incorporated, Technical Report. Golden Rules: Guidelines For The Use Of Gold On Connector Contacts. 2004. http://www.te.com/documentation/whitepapers/pdf/aurulrep.p df.

[17] Prabjit Singh, Larry Palmer and Mark Marnell, Robert Garner. 1960's SMS Card Connector Tabs. Materials and Process Engineering, S\&T Group Materials Laboratory, IBM Systems and Technology Group, IBM Almaden Research Center, Americas Service Delivery - EUS. IBM Corporation. September 7th of 2007. http://ibm-1401.info/SMS_Tabs_IBM_Report_Dec2007.pdf.

[18] Gold price. http://goldprice.org/. 